\title{
DIGITAL GANGRENE AS THE INITIAL PRESENTATION OF SYSTEMIC LUPUS ERYTHEMATOSUS WITHOUT SECONDARY ANTIPHOSPHOLIPID SYNDROME: CASE REPORT
}

\author{
Mushabab A Alghamdi ${ }^{1,}, M D$ \\ Department of Medicine, college of Medicine, University of Bisha, Bisha City, KSA.
}

\begin{abstract}
This is a case of a 28-year-old female presented with an extensive cutaneous gangrene of her fingers and toes with history of a livedo reticularis rash in both lower limbs. Her work-up showed positive serology for Systemic Lupus Erythematosus (SLE). There were no other symptoms suggestive of SLE. Interestingly, the patient adequately responded to rituximab therapy. Such a case of digital gangrene as the initial presentation of SLE without secondary antiphospholipid syndrome has rarely been reported in the literature.
\end{abstract}

\section{INTRODUCTION}

Systemic lupus erythematosus (SLE) is a chronic inflammatory disorder affecting different organs and systems. Vascular injury is an important characteristic of SLE. Digital gangrene in SLE is a rare form of vascular injury and considered to be a severe complication of SLE that generally leads to digital amputation $(1,2)$. The mechanisms include vasculitis, premature atherosclerosis, vasospasm, and hypercoagulability related to antiphospholipid antibodies. This is a report of an adult female presented with digital gangrene as the initial presentation of SLE; such presentation is rarely reported in the literature. There was no evidence of antiphospholipid antibodies. Initially treated with glucocorticoid, anti-platelets, anticoagulation, and potent vasodilator agents. Surprisingly, her digital ischemia improved dramatically after tow cycles of rituximab (RTX) administration. Up to our knowledge, the dramatic response of digital ischemia in systemic lupus erythematosus (SLE) to rituximab (RTX) is rarely reported in the medical literature.

\section{CASE DESCRIPTION}

A 28-year-old female presented to the emergency department, complaining of a black discoloration of the tip of her fingers and toes which progressed over a period of 2 weeks and was associated with severe pain.
The patient reported a lower limb net-like rash (livedo reticularis) 1 month earlier but without any other associated symptoms. There was no previous history of joint pain, oral ulcers, hair loss, photosensitivity, or Reynaud's phenomena.

Based on the physical examination, the positive findings were observed in her extremities. In her right hand, the third and fourth fingers were cyanotic and gangrenous (figure1). In her left hand, the fifth finger was cyanotic and gangrenous (figure2). In her right foot, the tip of the big toe was cyanotic (figure3). In her left foot, the first and second toes were cyanotic (figure 3 ). The dorsal pedis artery was not palpable. Both her legs showed a livedo reticularis rash (figure4).

Laboratory findings were as follows: WBC: $2.45 \times 109 / \mathrm{L}, \mathrm{Hb}: 8.9 \mathrm{~g} / \mathrm{dL}$, platelet: $233 \times$ 109/L, Hct: 29.4\%, ESR: 115 mm/h, CRP: $99.9 \mathrm{mg} / \mathrm{L}$, trace proteinuria on urinalysis.

Immunologic studies revealed an ANA titer of $>1: 160$ (homogenous pattern),

ds-DNA titer of $>240$, c- and p-ANCA negative, and anti-beta $2 \mathrm{GP} 1-\operatorname{IgA} / \operatorname{IgM} / \operatorname{IgG}$ isotype were negative. Anti-cardiolepin antibodies and lupus anticoagulant were negative. Hypocomplementemia was observed (C3: 0,371 g/L, C4: 0,035 g/L; normal: $\quad 0.9-2 \mathrm{~g} / \mathrm{L}$ and $0.1-0.4 \mathrm{~g} / \mathrm{L}$, respectively) although rheumatoid factor was negative (table1). 
Table1: laboratory result

\begin{tabular}{ll}
\hline $\mathrm{WBC}$ & $2.45 \times 109 / \mathrm{L}$ \\
\hline $\mathrm{Hb}$ & $8.9 \mathrm{~g} / \mathrm{dL}$ \\
\hline platelet & $233 \times 109 / \mathrm{L}$ \\
\hline $\mathrm{Hct}$ & $29.4 \%$ \\
\hline $\mathrm{ESR}$ & $115 \mathrm{~mm} / \mathrm{h}$ \\
\hline $\mathrm{CRP}$ & $99.9 \mathrm{mg} /$ \\
\hline urinalysis & trace proteinuria \\
\hline ANA titer & $>1: 160$ (homogenous pattern) \\
\hline ds-DNA titer & $>240$ \\
\hline c-ANCA & \\
\hline p-ANCA & negative \\
\hline anti-beta 2 GP1-IgA/IgM/IgG isotype & negative \\
\hline Anti-cardiolepin antibodies & negative \\
\hline lupus anticoagulant & negative \\
\hline C3 & $0,371 \mathrm{~g} / \mathrm{L}$ \\
\hline C4 & $0,035 \mathrm{~g} / \mathrm{L}$ \\
\hline rheumatoid factor & negative \\
\hline
\end{tabular}

A review of the radiological work-up (computed tomography angiography) of the upper and lower limb arteries showed no evidence of occlusion, significant stenosis, or aneurysmal formation. Electrocardiographic, echocardiographic, and computed tomography (CT) imaging studies of the thorax did not show any pathological findings. Because the initial results from laboratory studies indicated a possibility of SLE with high disease activity, initial treatment was started with glucocorticoid (1 $\mathrm{mg} / \mathrm{kg} /$ day), aspirin (81 $\mathrm{mg} / \mathrm{day})$ intravenous prostaglandin (2 $\mathrm{mcg} / \mathrm{kg} / \mathrm{min}$ ), and intravenous heparin. After confirmation of SLE and rolling out the secondary antiphospholipid syndrome, we discontinued the intravenous heparin and continued the patient on steroids. The plan was to administer cyclophosphamide; however, the patient refused because she was worried about the side effects. As an alternative to cyclophosphamide, the patient started on rituximab (RTX) with two infusions of $1000 \mathrm{mg}$ at a 14-day interval. The clinical and laboratory response to treatment was observed

Table2: management plan

\begin{tabular}{|c|c|c|}
\hline$\bullet$ & Initial treatment & $\begin{array}{ll}- & \text { glucocorticoid }(1 \mathrm{mg} / \mathrm{kg} / \mathrm{day}) \\
\text { - } & \text { aspirin }(81 \mathrm{mg} / \mathrm{day}) . \\
\text { - } & \text { prostaglandin }(2 \mathrm{mcg} / \mathrm{kg} / \mathrm{min}) \\
\text { - } & \text { therapeutic heparin. }\end{array}$ \\
\hline$\bullet$ & Induction treatment & $\begin{array}{l}\text { rituximab (RTX) two infusions of } 1000 \mathrm{mg} \text { at a 14- } \\
\text { day interval. }\end{array}$ \\
\hline$\bullet$ & Maintenance treatment & $\begin{array}{ll}- & \text { glucocorticoid }(5 \mathrm{mg} / \text { day }) \\
\text { - } & \text { aspirin }(81 \mathrm{mg} / \mathrm{day}) . \\
\text { - } & \text { azathioprine }(100 \mathrm{mg} / \text { day }) . \\
\text { - } & \text { hydroxychloroquine }(200 \mathrm{mg} / \text { day })\end{array}$ \\
\hline
\end{tabular}

after RTX therapy. Laboratory evaluation revealed the following: ESR: 30, CRP: $2 \mathrm{mg} / \mathrm{dL}$, and normal levels of $\mathrm{C} 3$ and $\mathrm{C} 4$ complement levels. (Results from a complete blood count panel were unremarkable). A combined dosage of $100 \mathrm{mg} /$ day azathioprine (AZA) and $200 \mathrm{mg} /$ day hydroxychloroquine were added to the treatment protocol after two infusions of RTX therapy. In addition, the corticosteroid dosage which was started at $1 \mathrm{mg} / \mathrm{kg}$ was gradually tapered till it reached $5 \mathrm{mg} /$ day over the 3 -month period. Eventually, digital gangrenous lesions started to regress after the first cycle (5 months) of RTX therapy. A second cycle of RTX therapy was started during which a complete recovery of digital lesions and the regression of active disease signs and acute phase responses were seen. The patient has been in clinical remission with glucocorticoid (5 mg/day), aspirin ( $81 \mathrm{mg} /$ day), azathioprine $\quad(100 \quad \mathrm{mg} /$ day $), \quad$ and hydroxychloroquine $(200 \mathrm{mg} /$ day $)$ for the last 2 years (table2). 

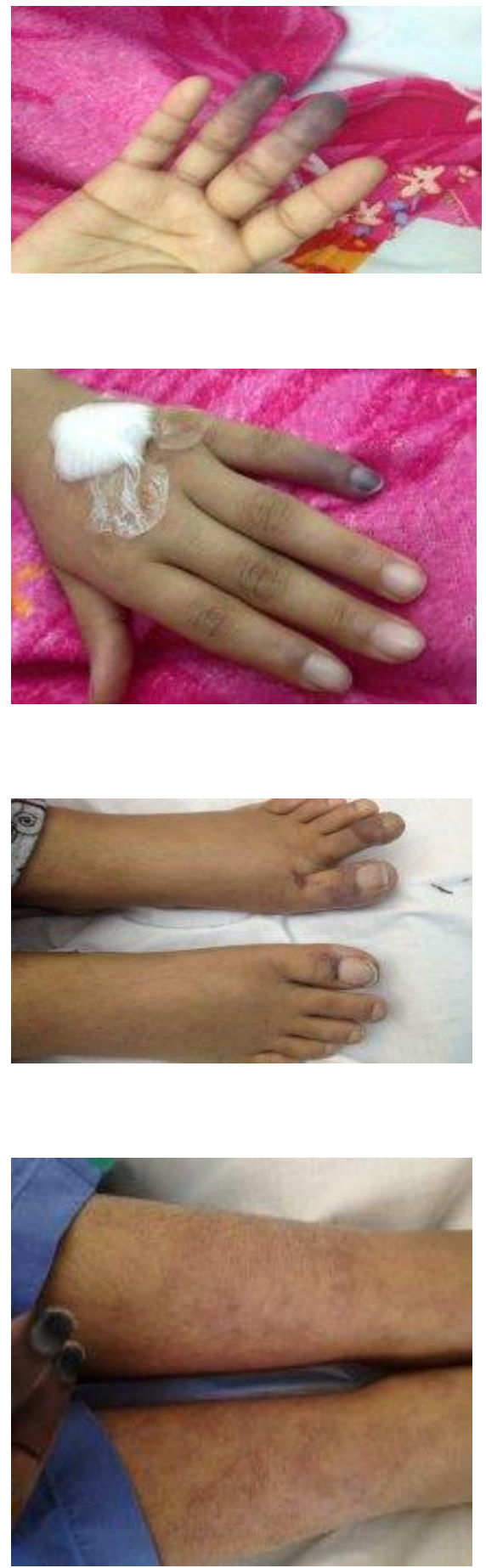

DISCUSSION

Digital gangrene as an initial presenting symptom of SLE is rarely reported. Most of the reported cases indicate the presence of antiphospholipid antibodies (3). The mechanisms involved in SLE with digital gangrene are complicated, including hypercoagulability, vasculitis, vasospasm, and atherosclerosis. Liu et al. found that 18 of 2684 SLE patients had digital gangrene, and they found
Figure1. cyanosis and gangrene of the third and fourth fingers of the right hand.

Figure2. cyanosis and gangrene of the fourth finger of the left hand.

Figure 3. cyanosis of the tip of the big toe of the right foot And the first and second toes of the left foot.

Figure 4. livedoreticularis rash.

that a long disease duration, Raynaud's phenomenon, and elevated serum CRP were independent predictive factors for SLE to develop digital gangrene. All the 18 patients were treated with cyclophosphamide, although eight cases failed and ultimately received digital amputation (4). Jeffery et al. observed in a cohort study that the prevalence of critical peripheral ischemia in SLE patients was $1.4 \%$. All of these had active 
disease and positive antiphospholipid antibodies with one patient responding to Rituximab therapy (5). Zieaa et al. reported a case of a 12-year-old girl presented with digital gangrene as the initial symptom of SLE and treated with steroids and mycophenolate mofetil (2). Orhan et al. reported a case of SLE and jaccoud arthritis in a patient who developed digital ischemia which improved after rituximab therapy (6).

In conclusion, digital gangrene as an initial presenting symptom of SLE is rare. a long disease duration, Raynaud's phenomenon, and elevated serum CRP were independent predictive factors for SLE to develop digital gangrene. Either cyclophosphamide, mycophenolate mofetil,or rituximab (RTX) can be a treatment option. Lastly, our patient presented with digital gangrene as the initial presentation of SLE without evidence of secondary antiphospholipid syndrome. She did not show any other signs or symptoms of SLE and eventually responded to rituximab therapy.

\section{ACKNOWLEDGEMENT}

The authors would like to thank Enago (www.enago.com) for the English language review.

\section{REFERENCES}

1. Adelowo O, Olaosebikan H, Ajani W, Omosebi (2012). Digital gangrene as the initial presentation of systemic lupus erythematosus. BMJ Case Rep.bcr2012006259.

2. Ziaee V, Yeganeh $\mathrm{MH}$, Moradinejad $\mathrm{MH}$ (2013). Peripheral gangrene: A rare presentation of systemic lupus erythematosus in a child. Am J Case Rep. AJCR.889290.

3. Asherson RA, Cervera R, Shoenfeld Y (2007). Peripheral vascular occlusions leading to gangrene and amputations in antiphospholipid antibody positive patients. Ann N Y Acad Sci.1108:515-29.

4. Liu A, Zhang W, Tian X, Zhang X, Zhang F, Zeng X (2009). Prevalence, risk factors and outcome of digital gangrene in 2684 lupus patients Lupus.1177/0961203309106643.

5. Jeffery RC, Narshi CB, Isenberg DA (2008). Prevalence, serological features, response to treatment and outcome of critical peripheral ischaemia in a cohort of lupus patients, Rheumatology 47( 9):1379-83.

6. Orhan Küçükşahin O, Düzgün N, Okoh AK, Kulahçioglu E (2014). Response to rituximab in a case of lupus associated digital ischemia. Case Rep Rheumatol.10.1155/2014/763608. 